\title{
Manejo e uso comum dos recursos naturais em populações quilombolas no Vale do Rio Capim
}

Maria Betanha Cardoso Barbosa - Mestre em Planejamento do Desenvolvimento (NAEA-UFPA) e Professora da Secretaria de Estado da Educação. E-mail: betanhabarbosa@hotmail.com

Rosa Elizabeth Acevedo Marin - Doutora em História Social e Professora do Núcleo de Altos Estudos Amazônicos. E-mail: ream30@hotmail.com

\section{Resumo}

Este texto destaca o sistema de uso comum de recursos naturais nas comunidades quilombolas de Taperinha, Sauá-Mirim e Nova Ipixuna localizadas no sudeste do Município de São Domingos do Capim, no Pará, Brasil. As comunidades encontran-se no local mais desmatado da margem do rio Capim. De acordo com a memória dos idosos, na abundância de recursos naturais, a comunidade os manejou sem regras e normas de uso. Entretanto, no período da escassez, foi necessária a elaboração de arranjos, a fim de ordenar a gestão dos recursos, para mantê-los. Essas regras e normas existem enquanto mecanismos de manejo dentro do território da comunidade, os quais passam a ser apropriados pelas famílias, segundo o despertar do sentimento de pertença, regido por estratégias de uso e sobrevivência. Assim, o uso deriva de uma ancestralidade que permite definir espaços de coleta, de caça e de cultivo. As normas e as regras emergem segundo a noção de território estabelecida pelo grupo, dando liberdade aos que podem acessar os recursos e, ao mesmo tempo, impondo regras ao seu consumo.

\begin{abstract}
This text outlines the system of common use of natural resources in quilombola communities of Taperinha, Sauá-Mirim and Nova Ipixuna. Situated in the southeastern of the São Domingos do Capim city. The communities are located in the most deforested area of the Capim River bank. According to the memory of the elderly, in the abundance of natural resources, the community handled without rules and norms of use. However, in times of scarcity, it was necessary to elaborate arrangements in order to sort the management of resources, to keep them. These rules and standards exist as management mechanisms within the territory of the community, which become incorporated by the families, by the awakening of the feeling of belonging, governed by strategies of use and survival. Thus, the use derives from an ancestry that defines spaces for gathering, hunting, farming, etc..The standards and rules emerge according to the notion of territory established by the group, giving freedom to the ones who can access resources and at the same time, imposing rules to its utilization.
\end{abstract}

\section{Palavras-chave}

Sistema de uso Comum. Quilombola. Recursos naturais.

\section{Keywords}

Common Use System. Quilombola. Natural Resources. 


\section{INTRODUÇÃO}

O uso comum de recursos naturais configura uma marcante característica das "populações tradicionais" na Amazônia, reconhecidas legalmente como “povos e comunidades tradicionais" (Decreto 6.040 de fevereiro de 2007). Neste sentido, distinguem-se por singularidades étnicas indígenas, quilombolas e formas identitárias outras como quebradeiras de coco babaçu, ribeirinhos, seringueiros, faxinalenses, fundo de pasto, entre outras. Este artigo vem contribuir para os estudos sobre os sistemas de uso comum de recursos naturais, permeado de estratégias particulares de reprodução, pelos atores sociais, na Região Amazônica, com destaque para as populações tradicionais do rio Capim.

O vale do rio Capim evidencia uma antiga ocupação humana que abrange o período do pré-contato, do contato e do pós-contato com civilizações de outros continentes. Todavia, é somente após a segunda metade do século XX, com a abertura da BR-010 (Belém-Brasília), (HÉBETTE; ACEVEDO MARIN, 1979) e, posteriormente, com o estabelecimento de políticas territoriais (COSTA, 1998), que a região do rio Capim será alvo de pressões migratórias de empresas madeireiras, agropecuárias e do extrativismo mineral ${ }^{1}$.

A exploração dos recursos naturais em grande escala gradativamente passou a impor uma lógica singular de ocupação para as margens do rio Capim. "As populações tradicionais" (os primeiros ocupantes desta região e que dela são intrínsecos), sobretudo a partir do contexto da colonização e, mais drasticamente, do pós-construção da Belém-Brasília, necessitaram interagir com os novos atores sociais introduzidos. Esta nova dinâmica de integração, interação e ocupação agregou uma exploração mais intensa dos recursos naturais, que repercutiu no território e nas formas produtivas. As expressões coexistentes passaram a desenvolver uma economia baseada fundamentalmente na agricultura camponesa, centrada no cultivo da mandioca, destinado à produção de farinha, além da continuidade das práticas extrativistas.

A área desta pesquisa localiza-se no baixo rio Capim, no domínio territorial do município de São Domingos do Capim, nordeste do estado do Pará; especificamente nas comunidades de Sauá-Mirim, Nova Ipixuna e Taperinha. Observa-se que $83,22 \%$ do território de São Domingos do Capim estão dentro

Vale ser ressaltado que pesquisas acerca do pré-contato, nesta região do Capim, ainda são muito insipientes. Aqui, partiu-se, fundamentalmente, do período compreendido entre a colonização até a atualidade. da bacia do rio Capim (LIMA, 2007, p. 138).As comunidades de Taperinha, Nova Ipixuna e Sauá-Mirim localizam-se no sudeste do município de São Domingos do Capim, com uma extensão territorial de 759 hectares.

Os grupos sociais de Taperinha, Nova Ipixuna e Sauá-Mirim se autoidentificam como quilombolas. O quilombo capinense apresenta uma conotação geográfica ou territorial de comunidade, visto que a relação com o lugar reflete as relações sociais e arranjos no uso dos recursos. Praticam uma agricultura itinerante centrada no cultivo da mandioca e em atividades extrativas, que se distinguem em caça, pesca e recursos florestais (madeireiros e não-madeireiros). Sendo que cada comunidade apresenta um exercício específico de uso diferenciado dos recursos, relacionado à distribuição espacial dos ambientes em seus respectivos territórios. Assim, as territorialidades delineadas obedecem aos aspectos da relação entre os atores sociais e da interação entre estes e os recursos naturais. Estas relações e interações são baseadas no sistema de uso comum, em um território coletivo, territorializado segundo limites físicos e simbólicos, que demarcam o acesso e o uso, em cada comunidade, aos ambientes dispostos.

Neste sentido, a indagação principal da pesquisa questionava a presença de um modelo de arranjo definido pelo sistema de regras e normas entre as comunidades. Desta forma, objetivou-se comparar os arranjos quanto ao uso comum de recursos entre as três comunidades, como também, identificar e relacionar o processo de territorialização. A partir destas indagações, optou-se pelo método comparativo, seguido da pesquisa etnográfica, com técnicas de coleta de dados, como a história oral, observação participante, aplicação de questionário, diário de campo, entrevistas, mapas coletivos e individuais; fatores que subsidiaram os dados apresentados neste artigo, a qual acompanha a divisão detalhada a seguir, além da Introdução, segundo os capítulos e temas abordados.

\section{FORMAS DIFERENCIADAS DE ARRANJOS NO USO DE RECURSOS COMUNS}

$\mathrm{Na}$ atualidade, a discussão sobre o uso de recursos comuns adquiriu proporções fundadas no nível de degradação em que se encontram, pelas sociedades contemporâneas, em decorrência do seu uso excessivo. O recurso, seja de origem natural ou antrópica, terá formas variadas de uso, podendo enquadrar-se 
em uso coletivo, uso privado ou uso por meio de co-gestão. Em um sentido de que a sociedade ou grupo social apresenta formas específicas de utilizar os recursos encontrados em seu território de vivência, como bem coletivo.

A tese levantada sobre esta temática partiu de Hardin (1968), no livro a Tragédia dos comuns. O dilema dos comuns propiciou questionamentos acerca da racionalização individual como contraponto à racionalização coletiva, no uso dos recursos. Hardin demonstrou que os recursos naturais de uso comum, como a atmosfera, os rios, os parques e os oceanos, estariam sentenciados a exaustão, por consequência do livre acesso aos mesmos, em decorrência de uma falta de regras para o acesso.

Assim, entre agricultores, pescadores e pastores, ou seja, entre os usuários que manejam os recursos pelo livre acesso, haveria a maximização do uso e, como consequência, a degradação do mesmo. Para evitar esta situação limite, Hardin (1968) propôs a privatização dos recursos ou a transformação dos recursos comuns em bens públicos, em que o direito de regulação caberia às instituições geridas pelo Estado.

Neste contexto, sob tais regimes, com o acesso e o uso restritos e regulados evitar-se-ia o uso exaustivo dos recursos. Sendo assim, Hardin tornouse empecilho ao regime de uso comum de recursos, o que acabou provocando críticas ao mesmo.

Outras contribuições teóricas, um tanto mais otimistas sobre o uso de recursos comuns, posteriores às de Hardin, demonstraram o sucesso na gestão coletiva de bens comuns, a partir da elaboração de regras, para garantir o acesso a todos. Compartilhando valores, Ostrom (1998) fundamenta-se na necessidade de se estabelecer regras e normas, criadas a partir de instituições ${ }^{2}$, que servem para coibir ou aplicar sanções aos indivíduos do grupo, como uma espécie de modelo de comportamento social pré-estabelecido.

Segundo Ostrom (1998, p. 9), "regras podem melhorar a reciprocidade por fazer comprometimentos mútuos mais claros e concisos". Para a definição de interesses comuns, a autora destaca que o comportamento do grupo de usuários, a estrutura do sistema de recursos, as regras de acesso para manejar o recurso e os resultados obtidos estruturam o corpo da teoria dos recursos comuns.

Instituições, na definição de Ostrom apud Schmitz (2006, p. 10) "são um conjunto de regras de trabalho que determinam, entre outros, os participantes, as ações permitidas ou proibidas, as informações necessárias e a distribuição de benefícios".
Mcken e Ostrom (1995) e Feeny et al. (2001), em contraposição ao dilema dos comuns, trabalham com o conceito de "propriedade comum", apoiado em diferentes regimes de propriedade, de acordo com a concepção de cada autor.

O entendimento do conceito de "propriedade comum" parte da formulação de regras ou direitos instituídos, para organizar o manejo dos recursos de uma comunidade. Tais regimes de propriedade, na verdade, seriam os arranjos organizados por meio de instituições coletivas para uso, manejo e propriedade dos recursos naturais (TCHÉ, 2003 apud MCKEN, 2000).

Deve-se salientar que dentre os recursos de propriedade comum incluem-se os peixes, vida selvagem, águas superficiais, pastagens e florestas, como também recursos antrópicos utilizáveis (FEENY et al., 1990; OSTROM; WALKER, 1994).

Segundo Feeny et al. (1990), o regime de propriedade é uma categoria relevante para o estudo e compreensão do manejo de recursos comuns. Deve-se dar atenção aos arranjos institucionais que regulam o uso e acesso dos recursos. Neste sentido, o autor destaca duas características quanto à natureza dos recursos: a excluibilidade e a subtraibilidade, que correspondem, respectivamente, à dificuldade em se excluir usuários do uso de um bem e à quantidade de subtração de um usuário, em relação ao conjunto da comunidade, sobre a disponibilidade de um recurso.

Com relação ao direito de propriedade, Feeny et al. (1990) distinguem quatro categorias básicas:

a) o acesso livre: quando não há direito de propriedade definido. Tornandose sem regras, assim, o acesso aos recursos;

b) a propriedade privada: o direito de acesso e o uso são individuais ou restritos a uma corporação;

c) a propriedade comum: o acesso ao recurso é garantido por uma comunidade e seus usuários através de um código de regulação de uso, que possui o direito de excluir e/ou coibir o acesso de uso a outros usuários;

d) a propriedade estatal: quando o acesso e uso são regulamentados pelo Estado.

Quanto ao espaço rural brasileiro, há a presença de todas as quatro categorias básicas de propriedade, no manejo dos recursos naturais, nas atividades extrativistas, em que os modelos podem se sobrepor, como na agricultura, na qual a produção camponesa deriva de regime de propriedade comum, e a nas empresas 
agropecuárias, que deriva de regime de propriedade privada. Neste sentido, a natureza individualista e concentradora da propriedade privada convive com o sistema de uso de recursos comuns de "populações tradicionais"3.

Estes grupos sociais adaptados ao ambiente desenvolveram estratégias políticas e econômicas para garantir sua permanência e sustentabilidade no território, por meio dos sistemas de uso comum. Para Godelier (1989, p. 110), “as formas de propriedade de um território são, pois, ao mesmo tempo, uma relação com a natureza e uma relação entre os homens". Almeida (1989) evidencia o uso de recursos como estratégia de resistência de pescadores, artesãos, quilombolas, caboclos-ribeirinhos, que, pela organização e destino da produção, são considerados como populações camponesas. Para as quais Abromovay (1998, p. 130) considera que os laços locais, os vínculos de natureza personalizada e o caráter extraeconômico das próprias relações de dependência social explicam as particularidades do campesinato.

O sistema de uso comum, diante das especificidades ambientais e históricas do território brasileiro, caracteriza-se por formas diferenciadas de organização do território. Esses camponeses impunham o uso comum não apenas como necessidade produtiva, mas também por razões políticas e pela necessidade de garantir a preservação do grupo.

Almeida (1989, p. 173) destaca o uso coletivo dos recursos, em áreas de colonização antiga ou recente, como meio de coesão e estratégia de sobrevivência de grupos sociais, excluídos da estrutura agrária, oficializada pelo Estado e pelo capital. Considerando que "os sistemas de uso comum tornaram-se essências para estreitar vínculos e forjar uma coesão capaz, de certo modo, de garantir o livre acesso a terra, frente a outros grupos sociais mais poderosos e circunstancialmente afastados". Tornam-se, então, alvo do discurso do capital da agroindústria, que denomina estas "ocupações especiais" como áreas improdutivas (ALMEIDA, 1989; OLIVEIRA, 2004).

$\mathrm{Na}$ Amazônia, o uso de recursos comuns é praticado por diferentes segmentos das "populações tradicionais", sendo encontrado entre índios, seringueiros, caboclos-ribeirinhos, pescadores e quilombolas. Almeida (1989) cita o exemplo dos campos marajoaras ou pastos comuns utilizados na criação

O conceito de "população tradicional", aqui trabalhado, partiu da interpretação de Almeida redefinidas situacionalmente numa mobilização continuada, assinalando que as unidades sociais em jogo podem ser interpretadas como unidades de mobilização". de reses em terras soltas. Entre as populações camponesas amazônicas, a partir de observações e experimentações, desenvolve-se um extenso conhecimento dos processos naturais (DESCOLA, 1990; POSEY; ANDERSON, 1990). O uso de recursos comuns compreende formas diversas de manejo responsáveis por relações sustentáveis com o ecossistema. Assim sendo, são extensas as relações construídas com a natureza pelas populações rurais amazônicas.

Nos quilombolas do Capim é quase uma regra o uso coletivo de recursos, em decorrência das estratégias de domínio do território. O modelo comunitário de acesso aos recursos naturais é gerador de formas socialmente mais equitativas de vida, ao mesmo tempo em que tece um conjunto de redes sociais intracomunidade e extra-comunidade (SCOLES, 2005). Portanto, na Amazônia, práticas de uso de recursos comuns, em territórios coletivos, repassadas pelas populações tradicionais, cujas estratégias de reprodução social estão ligadas às atividades extrativas, comprovam a eficácia do modelo sustentável e, ao mesmo tempo, exemplificam sob variadas formas de organização e de controle do território, o uso comum. Contrariando, assim, a tese dos grandes proprietários fundiários acerca da ineficácia do modo de produzir camponês e, a hipótese pessimista da “Tragédia dos comuns", de Hardin.

\section{COMUNIDADES QUILOMBOLAS DO CAPIM}

Os dados demográficos computam uma população total de 210 habitantes, distribuídos em 37 unidades domésticas. Taperinha possui o maior número de habitantes (121), seguida por Sauá-Mirim, com 62 habitantes. Com menor população, há Nova Ipixuna, com 27 habitantes. Correlação observada no Gráfico 1, que revela que Taperinha abriga 58\% da população total, seguida por Sauá-Mirim, com 29\% e, com menor percentual, Nova Ipixuna, com 13\% da população total.

Nas comunidades, entre os grupos domésticos, há o predomínio de determinadas famílias, como, por exemplo, os Luz, no Sauá-Mirim, e os Santos, em Taperinha e Nova Ipixuna. Apesar de possuir maior demografia, em Taperinha não houve acréscimo de espaços naturais (território): cada comunidade permaneceu com a divisão que lhe coube, desde sua ocupação.

A comunidade de Taperinha também se destaca, ainda de acordo com a Figura 1, em relação às unidades domésticas, pois concentra um total de 53\% 
das unidades domésticas. Seguida de Sauá-Mirim, com 30\% das unidades, e, com menor percentual, há Nova Ipixuna, com 17\% das unidades domésticas. Contudo, as regras de acesso à moradia, em Taperinha, são mais flexíveis do que em SauáMirim e Nova Ipixuna.

O senhor Henrique e a senhora América não colocam entraves ao "retorno dos que partiram". Remetendo Taperinha a uma constância na entrada e saída de seus habitantes, a uma mobilidade espacial recorrente.

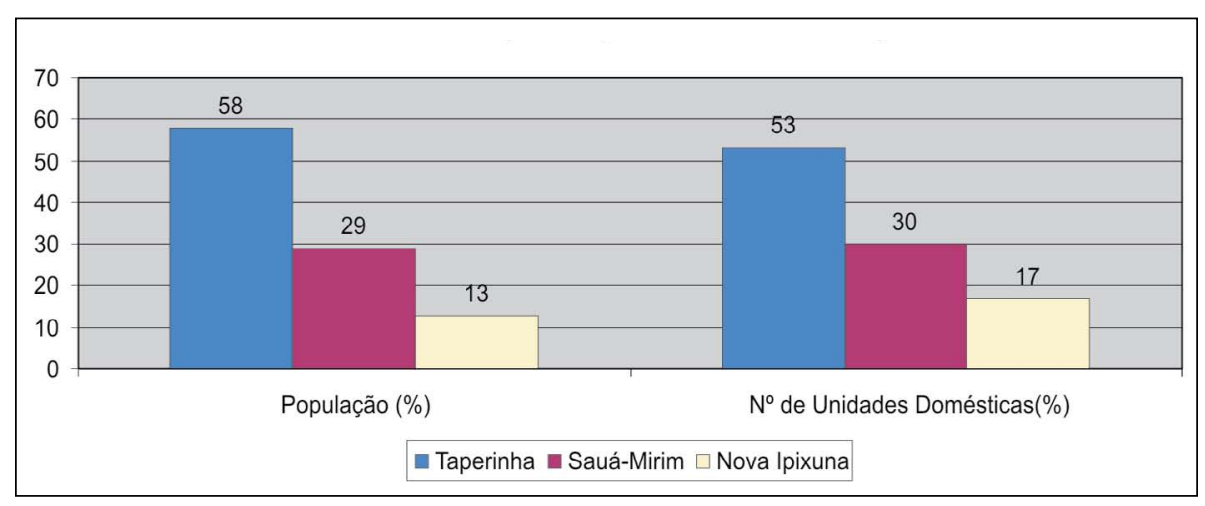

Figura 1. População quilombola e unidades domésticas distribuídas entre as conunidades de Taperinha, Sauá-Mirim e Nova Ipixuna, 2008.

Fonte: Pesquisa de campo (2007).

\section{MEMÓRIA DO USO DOS RECURSOS NATURAIS}

O território das comunidades capienses mantém a partilha dos bens naturais por meio do uso comum de recursos naturais, seguindo uma ordenação pelo tempo, pois a disponibilidade dos recursos torna-se referência nessa análise. Ao imprimir uma linha do tempo, na comunidade, verificamos que houve mudanças nas formas de uso e de recursos. Usa-se, como parâmetro de diferença, o passado e o presente, entre os idosos, sendo possível abstrair uma ordenação entre os recursos escassos, extintos e abundantes.

É comum lembrar-se da abundância existente no passado, comparada à escassez observada no presente, aparentes no teor do discurso proferido pelos interlocutores. Questionou-os, neste sentido, acerca dos recursos naturais oferecidos pela floresta, utilizados e/ou manejados tanto pelos antepassados quanto pelos interlocutores da pesquisa.
Em depoimento à autora, o senhor Vergino dos Santos enfatizou este aspecto, ao fazer comparação entre a oferta de recursos naturais no passado e na atualidade:

Nessa terra tinha muita madeira, frutas, muita mata com caça, os igarapés serviam com muito peixe, o meu pai saía uma noite pra caçar e trazia: paca, tatu, catitu, veado, cutia, preguiça. E a pesca então: bastava cercar o igarapé e não demorava pra gente conseguir muito peixe. Dava pro nosso almoço, jantar e ainda distribuía com nossos parentes. Hoje o meu filho sai, passa a noite toda na caça e não consegue nada, às vezes um tatu. Os peixes também sumiram desses igarapés, até do Capim. Antes a gente jogava o anzol e logo batia o peixe, hoje se eu quiser peixe é mais fácil comprar.

O senhor Henrique dos Santos compactua destas lembranças, da abundância dos recursos naturais extraídos por seus ancestrais, tal como pode ser visto no depoimento à autora:

Aqui tinha muita riqueza, muita fruta, caça, madeira. Meu pai tirava e vendia na foz do Pirajauara. Nesse tempo, a gente não vivia só da farinha, passava o correio e comprava ou meu pai trocava por outras coisas, como querosene, peixe seco. Mas tinha tudo que era fruta, e madeira então, dava pra fazer as casas e sobrava, tinha cupiúba, cedro, quaruba, e peixe nesses igarapés, no Simão, no Serra-Velha, no Naxi, no Buiuçu. Eu, moleque, tirava com meu pai: surumbi, acará, jacundá, piraiba, saranha, e no Capim tinha muito filhote e pescada.

Nestas narrativas, fica evidente a diversidade e a abundância, no passado, em comparação com a atualidade. Fundamentalmente, o passado é lembrado pela riqueza dos recursos naturais, em que se apontam as formas de uso, definidas pelos atores, segundo regras e normas, tal como narra a senhora América dos Santos, em depoimento à pesquisadora:

Meu avô aconselhava as famílias para não acontecer briga, cada um sabia como tirar a fruta, a madeira, a caça, pesca, sempre tirava pra comer, quando sobrava que vendia. Um não mexia na área do outro, no quintal, a várzea é de todo mundo, pode tirar o açaí, o cipó. Dessas frutas o que ainda tem muito é o açaí, mas a gente sempre guarda o açaí pra nossa alimentação.

Atenta-se, no conjunto deste texto, que as populações tradicionais possuem formas particulares de dividir os recursos presentes nos territórios de posse, que são capazes de promover a reprodução física e cultural do grupo. Diegues (1998) observou que a divisão do espaço, pelas populações caiçaras de jangadeiros e ribeirinhos, caracterizava-se pela apropriação comum dos recursos naturais, sob a forma do extrativismo vegetal (cipós, fibras e plantas medicinais, caça e pesca), em paralelo ao uso privado do espaço doméstico (casa, horta). 
Assim, exige-se dos indivíduos do grupo, a partilha de um código de postura para gerir o uso coletivo. Almeida (1989) afirma que este uso é baseado em normas específicas, instituídas e geralmente acatadas de maneira consensual, pelos membros do grupo social. Estas normas são construídas culturalmente, dentro de consensos sociais, quanto ao que seja considerável manejar de acordo com a oferta e/ou escassez de recursos, que, por isto, tornam-se partilhadas pela memória coletiva. Moldando e mantendo, deste modo, suas instituições.

Há de se considerar também que estas regras e normas existem enquanto mecanismos de manejo dentro do território da comunidade, os quais passam a ser apropriados pelas famílias, segundo o despertar do sentimento de pertença, regido por estratégias de uso e sobrevivência. Assim, o uso deriva de uma ancestralidade que permite definir espaços de coleta, de caça, de cultivo etc. As normas e as regras emergem segundo a noção de território estabelecida pelo grupo, dando liberdade aos que podem acessar os recursos e, ao mesmo tempo, impondo regras ao seu consumo ${ }^{4}$.

Em outro depoimento à pesquisadora, o senhor João Luz lembra a diversidade de espécies florestais que o território disponha. A madeira é uma atividade bastante explorada, desde o passado, e em razão da diminuição de espécies, o uso de regras para a sua extração possibilitou a conservação de algumas espécies, como se observa no relato abaixo:

Meu pai tirava madeira, tinha muita madeira, eu ainda tirei muita madeira tinha: marupá, anani, cedro, virola, para-pará, freijó, faveira, quaruba, o povo tirou, tirou e ficou pouca madeira. Pra tirar aqui agora tem que pedir pra mim. Mas da beira do rio eu não deixo tirar, é sagrado ninguém mexe. Eu não deixo derrubar árvore aqui. A gente tem que pensar nessas crianças, pra tirar madeira tem que ser com o consentimento dos mais velhos, e essas árvores que ainda tem uma, como o cedro e andiroba, a gente não deixa tirar. Já tem pouca madeira, pode tirar o cipó, pra fazer camboa, vassoura.

Ao se reportar para a fala do senhor João Luz, sobre o extrativismo da madeira, atenta-se para um momento em que o uso dos recursos dava-se pelo livre acesso. A presença de um grande comerciante de madeira na foz do rio Pirajauara, nos anos 1950, redirecionou as formas produtivas locais, em virtude da extração da madeira significar ganho imediato, comparando-se com a roça.

\footnotetext{
Este conjunto de regras, de acesso e de uso, é regido segundo noções estratégicas estabelecidas pelos grupos. Dentre estas, destacam-se as estratégias de apropriação, de uso e usufruto, de compartilhamento e troca, de preservação etc., que acabam por delimitar áreas específicas para a sua atuação (como é o caso das áreas destinadas à agricultura, das áreas sagradas, das áreas domésticas etc.).
}

O camponês, então, observou na extração madeireira, meios de responder às suas necessidades imediatas, de sobrevivência. A madeira extraída era trocada por alimento, querosene, tabaco etc.

Esta fase de uso de recursos pela forma de propriedade de livre acesso foi permissiva. O período, que compreende os anos de 1950 aos de 1960, foi de intensa exploração madeireira, que levou à escassez de espécies como o marupá, anani, cedro, virola, para-pará, freijó, faveira e quaruba.

$\mathrm{Na}$ abundância de recursos naturais, a comunidade os manejou sem regras e normas de uso. Entretanto, no período da escassez, foi necessária a elaboração de arranjos, a fim de ordenar a gestão dos recursos, para mantê-los.

O "consentimento dos mais velhos", para o uso aos recursos florestais, ilustra a regulação em seu uso. Em cada porção do território, seja em Taperinha, Nova Ipixuna ou Sauá-Mirim, a retirada de madeira acontece mediante aprovação dos idosos de cada comunidade. Esta posição, cabida aos idosos, deu sentido para a propriedade comum: mesmo com a participação coletiva, a ação dos idosos permitiu gerar um arranjo local, que expressa as necessidades e os interesses da comunidade, do coletivo.

Neste sentido, outros produtos florestais, como os cipós, podem ser coletados sem prévia autorização, permitindo verificar que tais regras de uso são regidas segundo normas específicas em cada comunidade.

Sobre a extração madeireira no rio Capim, Medina (2003) demonstra que esta prática econômica historicamente foi desencadeada a partir de necessidades externas, sobretudo, da capital do estado (Belém). Nos primórdios da prática extrativista da madeira, no Capim, observa-se que Belém vivenciava reformas urbanas, que deflagraram, para a região do Capim e seu entorno, uma demanda para suprir a carência desta matéria-prima. O Capim, então, deu suporte às reformas observadas no período de 1820 a 1935, na capital paraense.

No entanto, Medina esclarece que a exploração, no curso baixo do rio Capim $^{5}$ - área em que se localizam as comunidades em estudo ${ }^{6}$ - começou bem antes do que a exploração do alto Capim. Considerando que "[...] a madeira mais acessível, aquela próxima aos rios e igarapés, de onde saía boiando, já não era mais encontrada com facilidade no baixo Capim. Começava, então, o processo de ocupação e extração madeireira no alto Capim” (MEDINA, 2003, p. 310-311).

\footnotetext{
Os capienses utilizam como meio de localização, tendo como ponto de referência o curso do rio Capim, os termos alto Capim, às localidades próximas da nascente, e baixo Capim, às localidades próximas a foz. Utilizaremos, aqui, esta mesma denominação.

6 As comunidades em estudo (Taperinha, Nova Ipixuna e Sauá-Mirim) localizam-se no baixo Capim.
} 
A escassez, propiciada pela exploração desordenada, fez com que a comunidade estabelecesse regras e normas para garantir as espécies ainda presentes. O destino mercantil da extração madeireira foi dificultado tanto pela oferta irrisória quanto para regular o consumo.

A diminuição dos bosques florestais (flora) repercutiu diretamente na abundância das espécies de caça (fauna). Vários trechos da narrativa dos interlocutores demarcam o passado como sinônimo de abundância e o presente como sinônimo de carência, com destaque para a caça, tal como se observa no depoimento do senhor Vergino:

O que tem aqui é o que eu plantei, da capoeira já foi embora. Se nós tira e planta, tinha, mas só tira e não planta. Ficamos sem floresta, assim a caça foi acabando. A gente caçava era pra comer, nunca pra vender, isso não. O camarada limpa toda a área, o bicho não fica lá, o bicho gosta de lugar pra se esconder, por isso, a caça tá acabando, porque estão acabando com a floresta. No tempo do meu avô, do meu pai e quando eu ainda trabalhava, a gente sabia respeitar a natureza, não fazia desmate à toa.

Ainda sobre a caça, o senhor João Luz compara as ofertas de outrora com as de agora, reforçando, com isto, a memória do senhor Vergino dos Santos e permitindo realizar um parâmetro entre o consumo e a oferta da mesma, o que resulta em um baixo desempenho da caça como atividade extrativa na comunidade, e proporcionando mudanças na dieta alimentar, tal como segue:

Antes tinha mato pra caça se esconder. Hoje só uma capoeirinha, eu não deixo derrubar árvore aqui. Pega uma caça nesse ano e outra só no outro ano. Não é como no nosso tempo, que pegava uma hoje a outra amanhã. A carne que a gente comia, nesse tempo, era de caça. A carne que se come é o charque, a carne fresca de boi e o peixe salgado. Por isso, que o pessoal daqui não quer mais saber de caçar, fica a noite toda lá na espreita e não traz nada.

No entendimento dos entrevistados, o desmatamento é responsável pela baixa oferta de caça. Este fato trouxe hábitos alimentares urbanos para o grupo, além da considerável diminuição de certas espécies de caça (como paca, cutia, caititu, veado, tatu) para a dieta alimentar destas pessoas. Ao definir a proporção de caça entre "uma hoje e outra amanhã" e "uma hoje e outra só no outro ano", o senhor João Luz esclarece que a caça não responde mais pelas atividades extrativas efetivas do grupo.

Os locais de caça são lembrados como rotas definidas e pontos de chegada para a obtenção da fauna. Dentro do território, o conhecimento tradicional dos recursos delimitou os espaços reservados a esta prática extrativa.
Neste recorte de falas, é possível atentar para o simbolismo que a caça possuía para o grupo, como extrativismo mantenedor, a qual ocupava, inclusive, importância no campo dos saberes: a caça reproduzia-os por meio dos ensinamentos passados de pai para filho. Como a caça foi adquirindo uma posição periférica entre os mais jovens, atualmente ela é mais praticada como lazer, tal como pode ser visto nos relatos a seguir:

Meu pai nos levava pra várzea do Naxi, do Buiuçu e Serra-Velha. Era só chegar e logo a caça batia, não precisava ficar muito longe da casa. Até na capoeira grande tinha. Hoje é uma pacazinha aqui, um tatuzinho ali, quando tem. A gente não caçava quando a bicha tava prenha, ninguém aqui caçava um bicho com barriga. A caça era forte no inverno (Senhor Vergino).

Também os grandes caçadores daqui já se foram: meu avô, meus tios, meu pai, meus irmãos. Os filhos e netos acho que não sabem caçar. Esses homens daqui não querem mais caçar, a gente quer comer uma caça, mas eles não sabem como pegar o bicho, desaprenderam. Olha que os velhos ensinavam direitinho a esperteza de pegar o bicho (Senhora América).

Meu filho é bom caçador, o pai ensinou. Fico desejando comer uma caça, ele gosta de caçar, ele vai caçar lá pro Alto, aqui já foi tudo embora. Às vezes ele passa três dias no mato pra trazer uma caça, até a caça do Alto tá acabando (Senhora Bárbara).

A caça sempre foi pra comer, nunca se tirou pra vender, isso não, e hoje mesmo com pouca caça, não se pode tirar pra vender, se vender, pode vir um outro atrás que quer tirar pra comer com sua família, e aí como fica? Não é justo, por isso que quem ainda caça, caça pra comer. Se vender a gente chama e aconselha, mas aqui todos sabem que não podem vender a caça (Senhor João).

As comunidades quilombolas aqui abordadas localizam-se na porção do rio Capim, apontada por Pezzuti (2007), como sendo as margens mais degradadas de todo percurso, o chamado baixo Capim. Mesmo assim, a rara presença de recursos naturais não está relacionada à degradação derivada exclusivamente do seio da comunidade, mas compreende um contexto regional mais amplo.

A presença de grandes empreendimentos agropecuários (a partir da década de 1970), minerais (a partir da década de 1990) e de políticas de assentamento (com destaque para os assentamentos realizados nas décadas de 1970 e 2000), por órgãos oficiais como o INCRA, vem trazendo consequências significativas para esta área, inclusive, com mudanças expressivas na paisagem que margeia o rio Capim. A mata ciliar, as várzeas, os igapós e a terra firme dão lugar aos projetos de colonização, nos municípios de Aurora do Pará, Concórdia do Pará e São Domingos do Capim, e para os pastos destinados à pecuária, conforme pesquisa de campo. 
A caça possuía posição estratégica na alimentação, juntamente com a pesca, onde existem porções do território destinadas a estas atividades - as várzeas dos rios Buiuçu, Naxi e Serra-Velha são apontadas como local de caça. Ao percorrer essas várzeas, no trabalho de campo, pôde ser observada a presença de armadilhas e sinais impressos nos troncos de árvores, a fim de favorecer a localização e a mobilidade das trilhas de animais no território.

A caça quase sempre era destinada à alimentação e as regras estabelecidas não permitiam o comércio, muito menos a captura em período de reprodução. Mesmo na atualidade, com a caça em baixa, estas regras continuam rígidas. No entanto, os arranjos eficazes para o gerenciamento dos recursos naturais, no passado, não foram suficientes para impedir a escassez das espécies de caça, pois se deve considerar que pressões externas ao grupo também são grandes responsáveis por mudanças em suas dinâmicas.

Esta mudança no cardápio alimentar, seja pela falta de repasse dos conhecimentos sobre as habilidades da caça aos mais jovens, seja pela retração em sua oferta, redirecionou o papel da caça, o qual contribui atualmente de forma eventual à dieta do grupo.

A extração de recursos naturais consistia na captação de uma gama variada: caça, pesca, frutas, madeira etc. Com a diminuição desses recursos, outras atividades tornaram-se expressivas, como o cultivo da mandioca. Com o peixe presenciou-se situação semelhante à caça, como pode ser visto nos depoimentos abaixo:

O peixe, antes desse rio ficar envenenado, tinha muito. Quando meu pai saia pra pescar, trazia, filhote, tudo do Capim, agora ele só dá coceira. A água não serve mais pra beber, ela tem cor escura. A gente tomava água desse rio e não adoecia, agora até para o banho a água é ruim (Senhora América).

Hoje tirar peixe é difícil, antes pegava tucunaré, jacundá, surumbi, piau, pacu, piranha, gijum, tamuatá, jandiar, sarapó. Hoje pode pegar, mas é muita dificuldade, por que os peixes daqui do baixo foram todos pro alto (Senhor João).

Quando meu marido ia pescar trazia de dois a três paneiros cheios de peixe. Agora o cara vai e passa o dia todo com o anzol na mão e não traz peixe. É melhor o camarada ir pra roça, lá tem o que fazer. A nossa alimentação era mais de caça e da pesca (Senhora América).

Não podia vender o peixe, se o camarada pescasse muito ele tirava a bóia da família e distribuía com seus vizinhos, se fosse nos igarapés daqui de dentro, mas se fosse do Capim, ele podia vender (Senhora América).

Nesse igarapé Simão, eu jogava a camboa, ou usava cunambi e conseguia muito peixe, dava para alimentar as crianças e sobrava, eu dava pro vizinho. No Capim, aqui na frente de casa eu pescava filhote, acará, aracu, piau, baú, tuí, pescada branca, sarapó, camarão. Se eu quiser comer peixe, tenho que mandar comprar na DR. Todos aqui, fazem isso, compram, não pescam mais (Senhor Vergino).

A ictiofauna se apresentava pela variabilidade de peixes e camarão, em um raio de ação compreendido entre a margem do Capim, próximo à comunidade, e a rede hidrográfica, que serve o território, o que demonstra como a pesca constituiu parte significativa do extrativismo desenvolvido pela comunidade.

Uma das causas apontadas pelas famílias, ao considerarem a água do Capim "envenenada", é atribuída ao início da extração do caulim, minério extraído no alto. Para a comunidade, foi após a exploração mineral na região que a água do rio Capim tornou-se imprópria para o consumo, como também, para a reprodução da fauna aquática.

Tal como a caça, a pesca contribuiu significativamente para a dieta alimentar da comunidade. Em razão da baixa piscosidade nos igarapés e no rio Capim, a pesca passou a ser desacreditada, tornando-se sinônimo de tempo perdido. Em resposta a esta problemática, o extrativismo animal deixou de ocupar lugar relevante, como subsistência, e passou a ser praticado esporadicamente, voltado mais ao lazer dos jovens.

As normas que regulam a pesca resguardam o consumo cotidiano do grupo, visto que são impostas diferenças quanto ao domínio da origem do pescado, atribuindo-se valor ao lugar de captura do mesmo: os peixes capturados em igarapés e lagos, ou melhor, na rede de drenagem do território, são exclusivos para a alimentação do grupo. Se a produção diária ultrapassa as necessidades da família, deve-se distribuir o excedente entre seus pares.

Caso os peixes tenham sido retirados do rio Capim, mesmo margeando o território, adquire-se um sentido coletivo (mais amplo), ou seja, o Capim é de todos que moram em suas margens. Neste sentido, para o grupo, existe aí uma grande diferença de domínio. Por isto, os peixes aprendidos nos lagos e igarapés da comunidade são da comunidade. Portanto, vetados para a venda, enquanto os pescados no Capim podem ser comercializados. Na verdade, o que pode parecer uma restrição cultural está imbricado, simbolicamente, de enorme razão sustentável. Atenta-se para uma cautela que restringe o uso exagerado do recurso natural para fins mercantis. 
Os arranjos não são criados aleatoriamente. As sociedades desenvolvem continuamente normas e regras ${ }^{7}$ que guiam a relação com o ambiente, com a base de recursos dos quais dependem. Estas regras não são estáticas, pois são modificadas para atender às necessidades e as limitações impostas por fatores ecológicos, como também por fatores sociais, que muitas vezes podem ser extrínsecos ao grupo (CUNHA, 2004).

Normas e regras também resultam de valores atribuídos por estes grupos aos recursos naturais. Não se trata, todavia, de um valor cambial, muito menos diz respeito à quantidade de horas de trabalho humano gastos no manejo, mas se trata da atribuição de valor aos bens essenciais para a vida, como o uso da água, imbuídos de valores culturais, relacionados aos determinados recursos dispostos e consumidos pela comunidade.

Adicionam-se a este pressuposto, as frutas e as ervas medicinais, que surgem a partir da lembrança de seus sabores variados e de cura garantida para as enfermidades locais. A seguir, vêem-se depoimentos que contribuem para esta construção, acerca da variação e da disponibilidade dos recursos naturais, como frutas e plantas medicinais, no passado:

O açaí que tem aqui é o que a gente planta no quintal. Fora o açaí da várzea do Buiuçu e Naxi, o do mato já acabou. Foi derrubando a mata e foi acabando a fruta, nunca mais comi um piquiá, um bacuri (Senhor Vergino).

Tempo de invernada a gente saía pra catar as frutas. As que estavam no quintal do vizinho a gente tinha que pedir, pra tirar, mas se era fruta escassa como piquiá, pupunha, bacuri, cupuaçu, o vizinho não dava, por que é pra vender. A gente pede manga, caju, mamão. Essas a gente podia tirar do quintal do vizinho (Senhor Vergino).

Tinha muita fruta. A gente já sabia que em cada época se comia uma fruta, ela só dava naquela época. Agora, passa o ano e ninguém sabe o que é comer um cupuaçu, uma pupunha. Se tinha uma dor de barriga, uma constipação, uma febre aqui mesmo tinha remédio, era só ir no quintal ou pedir pro vizinho. Hoje pra tudo é uma pírula, essa coisinha pequena que tem que comprar, se não quiser ficar doente (Senhor Vergino).

O uso comum dos recursos é permeado por arranjos estratégicos, nos quais são impostas regras básicas para os períodos de abundância e de escassez, no que respeita às regras de uso $\mathrm{e}$ às regras de acesso. Na abundância, de acordo com as regras de uso, os grupos adotam posições flexíveis de comportamento e, na regras de acesso, as pessoas alheias ao grupo são apenas toleradas, permitindo-lhes o uso dos recursos apenas eventualmente. Na escassez, para a regra de uso, verifica-se que o grupo reforça as interdições, as quais são geralmente elaboradas segundo seus respectivos conteúdos culturais e, para as regras de acesso, observa-se que existem restrições de acesso aos recursos para as pessoas alheias ao grupo.
Tinha canela, capim-marinho, hortelã, alfavaca, casca de sucuúba, verônica, cidreira, capim-santo, boldo, quebra-pedra. Pra comprar remédio de farmácia, era muito difícil (Senhora América).

Pra vender a fruta só se for tirada do seu quintal. Da várzea não pode tirar pra vender, é de todos. Da várzea só pode tirar pra comer (Senhora América).

A continuidade das frutas regionais depende da permanência da floresta. $\mathrm{Na}$ medida em que se avança com o desmatamento, toda a flora e fauna que formam o sistema amazônico se desagregam. Em um ambiente mais cotidiano, em que a coleta de frutas possui limite territorial (em decorrência das demarcações), a carência é sentida rapidamente. Incluindo-se, neste contexto, o desmatamento oriundo da exploração madeireira e da abertura de roças.

A combinação no manejo de subsistência, mesmo regulado pelo grupo, não foi suficiente para impedir o avanço do desmatamento na comunidade. Havia certa auto-sustentação quanto à produção e a coleta de frutas e ervas medicinais. A lembrança de sabores regionais variados e dos males que necessitam de "pírula" para curar provoca uma sensação de desamparo entre as famílias, pois o território ou seus recursos naturais não mais respondem às necessidades emergenciais da comunidade.

Um passado de fartura conseqüentemente não condiz com a presença de conflitos internos no grupo, observados nas lembranças expostas sob narrativas dos membros das comunidades:

Cada um sempre soube onde deveria mexer. Aqui ninguém mexe no que não é seu. Quando faltava uma comida, a gente sempre se ajuda (Senhora América).

Às vezes uma família perdia toda a roça, então cada um ajudava com o que podia. Quando estava em falta uma fruta, uma madeira, aí só podia tirar se fosse necessidade. Mas sempre eles respeitaram (Senhor Vergino).

Nunca houve desavença entre nós. As vezes que houve, foi com vizinho querendo invadir nossas terras, um fazendeiro (Senhor Vergino).

Ninguém aqui pensa só em si. Ele pensa no outro, por que se ele tira pensando só nele, vai faltar pro outro. Por isso briga por roça, fruta, peixe, caça nunca teve (Senhor Henrique).

Nas lembranças destas populações do Capim, a cooperação não deixou espaço para conflitos. Mesmo em situações limites, as instituições e os valores criados foram suficientemente eficazes, a fim de sustentar uma convivência pacífica entre os indivíduos do grupo social. 
Ao término das indagações sobre as lembranças acerca do uso de recursos naturais no passado, deve-se atentar para a necessidade de recursos diversos e em quantidade suficiente para a comunidade fazer uso, possibilitando, inclusive, o comércio de seu excedente.

Os recursos com maior frequência de uso foram caça, pesca e os florestais, como frutas regionais e plantas medicinais cultivadas nos quintais (Anexo) ${ }^{8}$. Ressalta-se que o equilíbrio entre a disponibilidade dos recursos naturais e a população possibilita maior conservação dos mesmos.

O uso coletivo de recursos naturais e as instituições criadas para mantêlos são comuns no universo das comunidades de Taperinha, Sauá-Mirim e Nova Ipixuna, ressaltadas como ambientes com características naturais semelhantes. Deste modo, focalizou-se na identificação das formas de uso e gestão de recursos e nos mecanismos sociais que regulam o consumo e a manutenção do equilíbrio ecológico, a fim de os conhecer, contribuindo, assim, para minimizar a distância entre as futuras intervenções governamentais e a real necessidade das populações tradicionais locais.

\section{REFERÊNCIAS}

ABRAMOVAY, R. Paradigmas do capitalismo agrário em questão. São Paulo: Hucitec, 1998.

ACEVEDO MARIN, R. E.; CASTRO, E. R. Mobilização política de comunidades negras rurais. Domínio de um conhecimento praxiológico. Novos Cadernos NAEA, v. 2, n. 2, p. 73-106, dez. 1999.

ALMEIDA, A. W. B. de. Terras de preto, terras de índio, terras de santo. In: CASTRO, E.; HEBÉTTE, J. Na trilha dos grandes projetos: modernização e conflito na Amazônia. Belém: UFPA/NAEA, 1989. (Cadernos NAEA, n. 10).

CAYRES, G. M. V. Nazarenos e Marias do Capim: análise de gênero em uma comunidade amazônica. 1999. 225f. Dissertação (Mestrado em Planejamento do Desenvolvimento) - Núcleo de Altos Estudos Amazônicos, Universidade Federal do Pará, Belém, 1999.

COSTA, W. M. da. O Estado e as políticas territoriais no Brasil. São Paulo: Contexto, 1998. (Coleção Repensando a Geografia).

\footnotetext{
8 No Anexo há uma lista com os nomes populares e seus respectivos nomes científicos dos recursos naturais (fauna e flora) encontrados nas comunidades estudadas, que, na atualidade, são observados sob a égide da preocupante escassez.
}

CUNHA, L. H. da. 'Tragédia dos comuns’ à ecologia política: perspectivas analíticas para o manejo comunitário dos recursos naturais. Revista Raízes, Campina Grande, n. 1, v. 2, p. 10-26, jan./dez. 2004.

DESCOLA, P. Limites ecológicos e sociais do desenvolvimento da Amazônia. In: BOLOGNA, G. (Org.). Amazônia de adeus. Rio de Janeiro: Nova Fronteira, 1990.

FEENY, D. et al. A Tragédia dos Comuns: vinte e dois anos depois. In: DIEGUES, A. C.; MOREIRA, A. C. C. (Orgs.). Espaços e recursos naturais de uso comum. São Paulo: Nupaub/USP, 2001. p. 17-42.

FEENY, D.; BERKES, F.; MCCAY, B.J.; ACHESON, J.M. A tragédia dos comuns: vinte e dois anos depois. Trad. André de Castro C. Moreira. In: DIEGUES, A. C.; MOREIRA, A. C. C. (Orgs.). Espaços e recursos naturais de uso comum. São Paulo: Nupaub/USP, 2001, p.17-42.

GODELIER, M. Lo ideal y lo material: pensamiento, economías y sociedades. Madrid: Tourus, 1989.

HARDIN, G. The tragedy of the commons. Science, v. 162, n. 3859, 1968.

HÉBETTE, J.; ACEVEDO MARIN, R. E. Colonização para quem? Belém: NAEA/UFPA, 1979. 173p. (Amazônia, 1)

LIMA, A. M. M. de. O planejamento estratégico e a gestão da oferta hídrica baseados no estudo da paisagem, na bacia do rio Capim-PA. 2007. Tese (Doutorado em Desenvolvimento Sustentável do Trópico Úmido) - Núcleo de Altos Estudos Amazônicos, Universidade Federal do Pará, Belém, 2007.

MEDINA, G. A vida dirige o rio: cem anos de ocupação cabocla e extrativismo madeireiro no Alto Capim. 2003. 88f. il. Dissertação (Mestrado em Agriculturas Familiares e Desenvolvimento Sustentável) - Centro Agropecuário, Universidade Federal do Pará, Embrapa Amazônia Oriental, Belém, 2003.

MCKEAN, M.; OSTROM, E. Regime de propriedade comum em florestas: somente uma relíquia do passado? In: DIEGUES, A. C.; MOREIRA, A. C. C. (Orgs.). Espaços e recursos naturais de uso comum. São Paulo: Nupaub/ USP, 2001. p. 79-96.

OLIVEIRA, A. U. de. A. O campo no século XXI: território de vida, de luta e de construção da justiça social. São Paulo: Casa Amarela, 2004. 
PEZZUTI, J. Sessão Livre Atlas regionais: metodologia, estrutura e elaboração. In: ENCONTRO NACIONAL DA ANPUR, 12., 2007, Belém. Palestra proferida... Belém: ANPUR, 2007.

POSEY, D. A.; ANDERSON, A. B. O reflorestamento indígena. In: BOLOGNA, G. (Org.). Amazônia de adeus. Rio de Janeiro: Nova Fronteira, 1990. 